\title{
Metabolomics and Transcriptomics Analyses of Two Contrasting Cherry Rootstocks in Response to Drought Stress
}

\author{
Tian Wan ${ }^{1,+}$, Ying Feng ${ }^{1,+}$, Chenglin Liang ${ }^{2}$, Liuyi Pan ${ }^{1}$, Ling He ${ }^{1, *}$ and Yuliang Cai ${ }^{1, *}$ \\ 1 College of Horticulture, Northwest Agriculture \& Forestry University, No.3 Taicheng Road, \\ Yangling 712100, China; wtian2012@nwsuaf.edu.cn (T.W.); xtdyuer@163.com (Y.F.); \\ panliuyi314@126.com (L.P.) \\ 2 Haidu College, Qingdao Agricultural University, Laiyang 265200, China; lj12015lcl@163.com \\ * Correspondence: heliurui@nwsuaf.edu.cn (L.H.); yuanyicyl@nwsuaf.edu.cn (Y.C.); \\ Tel.: +86-18092249581 (L.H.); +86-15829636555 (Y.C.) \\ + These Authors equally contributed to the work.
}

check for updates

Citation: Wan, T.; Feng, Y.; Liang, C.; Pan, L.; He, L.; Cai, Y. Metabolomics and Transcriptomics Analyses of Two Contrasting Cherry Rootstocks in Response to Drought Stress. Biology 2021, 10, 201. https://doi.org/ 10.3390/biology10030201

Academic Editor: Eduardo Blumwald

Received: 6 February 2021

Accepted: 2 March 2021

Published: 6 March 2021

Publisher's Note: MDPI stays neutral with regard to jurisdictional claims in published maps and institutional affiliations.

Copyright: (c) 2021 by the authors. Licensee MDPI, Basel, Switzerland. This article is an open access article distributed under the terms and conditions of the Creative Commons Attribution (CC BY) license (https:// creativecommons.org/licenses/by/ $4.0 /)$.
Simple Summary: Drought is one of the main factors affecting sweet cherry yields, and cherry rootstocks can provide a range of tree vigor levels to better match sweet cherries with the characteristics of the soil. To investigate the molecular responses of the cherry rootstocks to water deficiency, we performed transcriptomic and metabolomic analyses of two contrasting cherry rootstocks-Mahaleb CDR-1 and Gisela 5. The results revealed that differentially expressed metabolites related to the pathways of cyanoamino acid metabolism and phenylpropanoid biosynthesis may be key factors in the difference in drought resistance in the two rootstocks. Moreover, six central metabolites-3cyanoalanine, phenylalanine, quinic acid, asparagine, p-benzoquinone, and phytosphingosine-were identified as potential biological markers of the drought response in cherries and may be key factors in the difference in drought resistance, along with caffeic acid and chlorogenic acid. Furthermore, we selected 17 differentially expressed genes as core candidate genes and the mechanism of a droughttolerant cherry rootstock (DT) in response to drought is summarized. This study can provide a valuable insight into the molecular mechanisms behind drought resistance and will be beneficial to those aiming to breed promising new cherry cultivars.

Abstract: Drought is one of the main factors affecting sweet cherry yields, and cherry rootstocks can provide a range of tree vigor levels to better match sweet cherries with the characteristics of the soil. To investigate the molecular events of the cherry to water deficiency, we performed transcriptomic and metabolomic analyses of Prunus mahaleb CDR-1 (drought-tolerant cherry rootstock (DT)) and $P$. cerasus $\times$ P. canescens Gisela 5 (drought-susceptible cherry rootstock (DS)), respectively. The results revealed 253 common drought-responsive genes in leaves and roots in DT and 17 in DS; 59 upregulated metabolites were explored in leaves in DT and 19 were explored in DS. Differentially expressed metabolites related to the cyanoamino acid metabolism pathway and phenylpropanoid biosynthesis pathway may be key factors in the difference in drought resistance in the two rootstocks. Moreover, six central metabolites-3-cyanoalanine, phenylalanine, quinic acid, asparagine, p-benzoquinone, and phytosphingosine-were identified as potential biological markers of drought response in cherries and may be key factors in the difference in drought resistance, along with caffeic acid and chlorogenic acid. We also selected 17 differentially expressed genes as core candidate genes and the mechanism of DT in response to drought is summarized.

Keywords: Prunus mahaleb CDR-1; P. cerasus $\times$ P. canescens Gisela 5; water deficiency; central metabolites; biosynthesis pathways; transcriptome

\section{Introduction}

Drought is among the most serious challenges to crop production in the world today. As a major abiotic stress, drought can severely affect the yield and quality of agricultural 
production systems [1-3]. The drought resistance of the sweet cherry (Prunus avium) rootstock remains an important tool for extending the site adaptability of cultivars in China, especially in the Loess Plateau region of northwest China [4,5]. Although knowledge of the physiological responses of Prunus species to drought is increasing [6-8], little is known about the link between drought tolerance and the associated foundations of metabolomes and transcriptomes. It is of great importance for breeders to understand the molecular responses of cherry or Prunus fruit trees to drought stress and to develop novel molecular approaches to enhance their tolerance to drought.

Different species respond differently to drought stress. Most cherry rootstocks are susceptible to water deficits, and drought tends to interfere with plant growth, reproduction, and the absorption and transport of nutrients [9]. Germplasms with contrasting drought tolerance are ideal materials, and the drought resistance of Prunus rootstocks is closely related to their genetic background [10]. In cherry production, the Mahaleb (P. mahaleb) and Gisela (hybrids of P. cerasus and P. canescens) series are both great potential rootstocks, with different genetic backgrounds and contrasting responses to drought [11]. The former is a drought-tolerant species that can survive in extremely dry conditions and a native species to Europe and Western-Asia in thickets on dry karst areas, which shows great potential for cherry rootstock breeding [11-13]; Mahaleb CDR-1 (P. mahaleb) is an important rootstock variety and is most widely used in northern China [4]. The latter is largely known as a drought-susceptible species; owing to its good properties, such as early fruitbearing and dwarfing, it is an important rootstock for breeding cherry seedlings and is popular with farmers in the world, especially Gisela 5 (P. cerasus $\times$ P. canescens) and Gisela 6 (P. cerasus $\times$ P. canescens $)[4,11,14]$.

From the point of view of system biology, performing omics joint analysis can be a good way of understanding the mechanism behind drought regulation in plants; such analyses have been widely used in modern biology to characterize the molecular responses of plants to abiotic stress [15]. Metabolomics can unravel these complex mechanisms by measuring the metabolites that participate in various biochemical processes. In response to abiotic stress, plants can regulate their metabolic networks and synthesize a series of metabolites that can help them repair the damage [16]. It is of great significance to reveal the mechanisms behind the plants' responses to stress. High-throughput transcriptome analysis, which focuses on transcripts with functional information in the plant genome, is widely used in the field of plant stress research [17] on plants such as Mongolian almond [18], Ginkgo biloba L. [19], and wheat [20]. Combining transcriptomics and metabolomics is an effective means of exploring the responses of plants to stress. You et al. [21] found that amino acid metabolism and abscisic acid metabolism and signaling play important roles in drought tolerance in sesame, and Pan et al. [22] underscored the significance of 23 core metabolic processes in annual ryegrass. In addition, multiomics has been used to study other abiotic stress responses related to temperature [23,24], nutrition [25], salinity [26], light $[27,28]$, and so on.

Our objective is to present a comprehensive overview of the metabolomes and transcriptomes of contrasting cherry rootstocks and to infer the core regulatory networks to reveal the relationships among metabolites and transcript pathways. This study can provide a valuable insight into the molecular mechanisms behind drought resistance and will be beneficial to those aiming to breed promising new cherry cultivars.

\section{Materials and Methods}

\subsection{Plant Material, Stress Treatment, and Sampling}

The experiments were conducted at Northwest A\&F University, Yangling, China $\left(34^{\circ} 20^{\prime} \mathrm{N}, 108^{\circ} 24^{\prime}\right.$ E). P. mahaleb CDR-1 (drought-tolerant cherry rootstock (DT)) and $P$. cerasus $\times P$. canescens Gisela 5 (drought-susceptible cherry rootstock (DS)) seedlings were obtained through cutting propagation, and the obtained cuttings were used as test materials with the same growth status and robust growth without pests and diseases. Drought resistance was assessed in a preliminary experiment that was consistent with 
the reported conclusions on the two rootstocks [11,12]. Biennial cutting seedlings were grown in a glasshouse with a day/night temperature of $28{ }^{\circ} \mathrm{C} / 18{ }^{\circ} \mathrm{C}$. Each genotype contained one stress group (SG) and one control group (CG): SG was used for drought stress treatment, and CG was used as a well-watered control. All genotypes were irrigated every 3 days to field capacity as needed, fertilized weekly with Hoagland's solution, and irrigated in the same manner before treatment. In this period, the soil moisture in the pots was maintained at about $75 \%$ of the field capacity. Then irrigation was stopped in SG, but watering continued in CG as before. Drought stress was monitored according to the leaf relative water content. Material was sampled at the first appearance of leaf wilting 10 days after drought stress. The leaf relative water content of drought-stressed plants was $65 \%$ in DT (vs. $89 \%$ in control) and $67 \%$ in DS (vs. $87 \%$ in control). Leaves and root tip tissues (about 1 to $2 \mathrm{~cm}$, including root cap, meristematic zone and elongation zone) were collected in three biological replicates for the transcript analysis, and leaf samples were harvested in six biological replicates for the metabolite analysis (Table 1). The harvested samples were immediately frozen in liquid nitrogen and stored at $-80^{\circ} \mathrm{C}$ until needed for further analyses.

Table 1. Experimental sampling code.

\begin{tabular}{|c|c|c|c|c|}
\hline Material & Tissue & Group & Samples for RNA-seq & Samples for GC-MS Tests \\
\hline \multirow{4}{*}{ DT } & \multirow{2}{*}{ Leaves } & Drought stress & $\begin{array}{l}\text { CDR-LS1, CDR-LS2, } \\
\text { CDR-LS3 }\end{array}$ & $\begin{array}{l}\text { CDR-LS1, CDR-LS2, CDR-LS3 } \\
\text { CDR-LS4, CDR-LS5, CDR-LS6 }\end{array}$ \\
\hline & & Control & $\begin{array}{l}\text { CDR-LCK1, } \\
\text { CDR-LCK2, CDR-LCK3 }\end{array}$ & $\begin{array}{l}\text { CDR-LCK1, CDR-LCK2, CDR-LCK3 } \\
\text { CDR-LCK4, CDR-LCK5, CDR-LCK6 }\end{array}$ \\
\hline & \multirow{2}{*}{ Root tip tissues } & Drought stress & $\begin{array}{l}\text { CDR-RS1, CDR-RS2, } \\
\text { CDR-RS3 }\end{array}$ & - \\
\hline & & Control & $\begin{array}{l}\text { CDR-RCK1, } \\
\text { CDR-RCK2, } \\
\text { CDR-RCK3 }\end{array}$ & - \\
\hline \multirow{4}{*}{ DS } & \multirow{2}{*}{ Leaves } & Drought stress & $\begin{array}{l}\text { G5-LS1, G5-LS2, } \\
\text { G5-LS3 }\end{array}$ & $\begin{array}{l}\text { G5-LS1, G5-LS2, G5-LS3 } \\
\text { G5-LS4, G5-LS5, G5-LS6 }\end{array}$ \\
\hline & & Control & $\begin{array}{l}\text { G5-LCK1, G5-LCK2, } \\
\text { G5-LCK3 }\end{array}$ & $\begin{array}{l}\text { G5-LCK1, G5-LCK2, G5-LCK3 } \\
\text { G5-LCK4, G5-LCK5, G5-LCK6 }\end{array}$ \\
\hline & \multirow{2}{*}{ Root tip tissues } & Drought stress & $\begin{array}{l}\text { G5-RS1, G5-RS2, } \\
\text { G5-RS3 }\end{array}$ & - \\
\hline & & Control & $\begin{array}{l}\text { G5-RCK1, G5-RCK2, } \\
\text { G5-RCK3 }\end{array}$ & - \\
\hline
\end{tabular}

DT, P. mahaleb CDR-1 (drought-tolerant cherry rootstock). DS, P. cerasus $\times$ P. canescens Gisela 5 (drought-susceptible cherry rootstock). CDR-LS, the leaf samples of DT in stress group; CDR-LCK, the leaf samples of DT in control group; G5-LS, the leaf samples of DS in stress group; G5-LCK, the leaf samples of DS in control group; CDR-RS, the root samples of DT in stress group; CDR-RCK, the root samples of DT in control group; G5-RS, the root samples of DS in stress group; G5-RCK, the root samples of DS in control group. 1, 2, 3, 4, 5 and 6 (the number at the end of each abbreviation) represent each biological replicate, respectively.

\subsection{RNA Sequencing and Functional Annotation}

Total RNA was isolated with TRIzol reagent (Tiangen Biotech, Beijing, China) according to the manufacturer's protocol. The RNA quality was controlled using NanoPhotometer spectrophotometer (IMPLEN, Westlake Village, CA, USA), Qubit 2.0 Flurometer (Life Technologies, CA, USA) and Agilent Bioanalyzer 2100 system (Agilent Technologies, CA, USA). A total amount of $1.5 \mu \mathrm{g}$ RNA per sample was used as input material for the RNA sample preparations. Sequencing libraries were generated using NEBNext Ultra RNA Library Prep Kit for Illumina (NEB, Ipswich, MA, USA) following the manufacturer's recommendations and index codes were added to attribute sequences to each sample. Briefly, mRNA was purified from total RNA using poly-T oligo-attached magnetic beads. Fragmentation was carried out using divalent cations under elevated temperature in NEBNext First Strand 
Synthesis Reaction Buffer (5X). First strand cDNA was synthesized using random hexamer primer and M-MuLV Reverse Transcriptase $\left(\mathrm{RNase}^{-}\right)$. Second strand cDNA synthesis was subsequently performed using DNA Polymerase I and RNase H. Remaining overhangs were converted into blunt ends via exonuclease/polymerase activities. After adenylation of $3^{\prime}$ ends of DNA fragments, NEBNext Adaptor with hairpin loop structure were ligated to prepare for hybridization. In order to select cDNA fragments of preferentially 150 200 bp in length, the library fragments were purified with AMPure XP system (Beckman Coulter, Beverly, LA, USA). Then $3 \mu$ l USER Enzyme (NEB, Boston, MA, USA) was used with sizeselected, adaptor-ligated cDNA at $37^{\circ} \mathrm{C}$ for $15 \mathrm{~min}$ followed by $5 \mathrm{~min}$ at $95^{\circ} \mathrm{C}$ before PCR. Then PCR was performed with Phusion High-Fidelity DNA polymerase, Universal PCR primers and Index $(X)$ Primer. At last, PCR products were purified (AMPure XP system, Brea, CA, USA) and library quality was assessed on the Agilent Bioanalyzer 2100 system.

cDNA libraries were built, and the qualified libraries were subjected to paired-end sequencing using the Illumina 4000 sequencer by Novogene (Beijing, China). Raw data reads were filtered to remove adapter sequences, reads containing more than $10 \%$ unknown bases, and low-quality sequences to generate clean data. The clean data were mapped to the reference genome [29] with HISAT. The expression of each gene was calculated and normalized by the corresponding fragments per kilobase of transcript per million mapped fragments (FPKM) with cufflinks. We selected differentially expressed genes (DEGs) by performing the negative binomial test in the DESeq package [30]. DEGs were annotated through comparison with previously annotated genes in public databases, the National Center for Biotechnology Information nonredundant database, the Swiss-Prot database, Gene Ontology (GO), and euKaryotic 87tssOrthologous Groups/Clusters of Orthologous Groups. Pathway analysis was performed with the Kyoto Encyclopedia of Genes and Genomes (KEGG) database.

\subsection{Quantitative Real-Time PCR ( $q R T-P C R)$}

The qRT-PCR was performed with a Life Technologies QuantStudio 5 using SYBR Premix Ex Taq Kit (Takara Biotechnology Co., Ltd., Dalian, China). Primers used for the qRT-PCR are listed in Table S1. The RT-PCR was performed under the following conditions: $95^{\circ} \mathrm{C}$ for $10 \mathrm{~min}$, followed by 35 cycles of $95^{\circ} \mathrm{C}$ for $3 \mathrm{~s}$, and $60^{\circ} \mathrm{C}$ for $30 \mathrm{~s}$. Each sample was analyzed in triplicate. ACTIN was used as a reference gene to normalize the relative expression of selected genes. The relative expression (fold changes) of 10 candidate genes was calculated with the $2^{-\Delta \Delta C t}$ method and translated to $\log 2$ fold changes to compare with the RNA-seq results.

\subsection{Metabolomics Data Processing and Analysis}

The mixed samples were subjected to gas chromatography-mass spectrometry (GCMS). Chroma TOF 4.3X by LECO Corporation and the LECO-Fiehn Rtx5 database were used to exact raw peaks, filter the data baselines, calibrate the baselines and peaks, perform deconvolution analysis, and integrate the peak areas. The retention time index method was used in the peak identification, and the retention time index tolerance was 5000. Principal component analysis (PCA) and orthogonal projections to latent structures-discriminant analysis (OPLS-DA) were performed with SIMCA (V14.1; MKS Data Analytics Solutions, Umea, Sweden). Central metabolites were selected based on the variable importance in the projection (VIP) and $p$ value. Metabolites with VIP $>1.0$ and $p<0.05$ were selected as central metabolites. Related pathways analysis was performed with KEGG (http / / www. genome.jp/kegg/, accessed on 10 April 2018), NIST (http//www.nist.gov/index.html, accessed on 10 April 2018), and MetaboAnalyst (http//www.metaboanalyst.ca, accessed on 10 April 2018). Quantitative values of central metabolites were used to calculate the Euclidean distance matrix (Euclidean short matrix). The full-chain approach was used to cluster the central metabolites, and the results were displayed as a heat map. An interaction analysis of central metabolites was performed using MetaScape (Cytoscape3.6.1). 


\subsection{DEGs and Conjoint Analysis of Central Metabolites}

Data on DEGs and differentially expressed metabolites were used for conjoint analysis and mapping to the KEGG database to identify the pathways in which genes and metabolites participated. The analysis also explored the common and different metabolic processes upstream and downstream involving genes and metabolites of the two genotypes. The results were used to infer the mechanisms behind their differential drought resistance.

\subsection{Screening of Core Candidate Genes and Bioinformatics Analysis}

Candidate genes for the drought response (mainly focusing on upregulated genes) were screened based on three factors: fold change, abundance of gene expression, and DEGs between the two genotypes. The DEGs were filtered by ta logarithm two-fold change $|\log 2 \mathrm{FC}| \geq 1$ and padj $<0.05$ as screening standards. GO terms and KEGG pathways fulfilling the criterion of a Bonferroni-corrected $p$-value $\leq 0.05$ were defined as significantly enriched in DEGs. BLAST E-value $\leq 10^{-5}$ and HMMER E-value $\leq 10^{-10}$ were set as select parameters. DEGs protein-protein interaction analysis was performed by STRING (confidence limits $\geq 700$ ) and visualized on Cytoscape3.6.1 software. GO classification, KEGG classification, interaction analysis of DEGs, and conjoint analysis of central metabolites and DEGs were used to further screen the core set of candidate genes. The bioinformation of the core candidate genes was analyzed, including the coding sequence, the amino acid sequence, protein properties, and subcellular localization prediction. Using the National Center for Biotechnology Information ORF finder, we obtained the coding sequence of each candidate transcription sequence. Protein subcellular localization prediction was done online (https:/ / wolfpsort.hgc.jp/, accessed on 10 April 2018), and the physical and chemical properties of predicted proteins were identified online as well (https://web.expasy.org/protparam/, accessed on 10 April 2018).

\section{Results}

\subsection{Transcriptional Characteristics of the Responses of Cherry Rootstock to Drought Stress}

The resulting set of 24 samples yielded more than 1.11 billion clean reads, and more than $75.3 \%$ of map rates were mapped to the cherry genome (Table S2). A total of 2070 DEGs were identified in DT, and 746 DEGs were identified in DS. Of these DEGs, 73 and 49 were explored in both rootstocks, in leaves and root tissues, respectively (Figure S1). The 365 upregulated DEGs (281 in leaves and 84 in roots) and 1705 downregulated DEGs (626 in leaves and 1079 in roots) were detected in CDR-1, while 150 DEGs (79 in leaves and 71 in roots) were upregulated and 605 (400 in leaves and 205 in roots) were downregulated in Gisela 5, respectively. Moreover, 253 and 17 DEGs were detected between leaves and root tissues, respectively, in CDR-1 and Gisela 5. Many transcription factors (TFs) and genes related to enzymes were downregulated in both genotypes. Only some TFs were upregulated, including IFH, ninja-family protein AFP3, CCR4-associated homolog, and COL domain in leaf tissues and extensin-3-like, U-box domain-containing protein 21-like, and chitotriosidase-1-like in roots (Table S3). Most DEGs were enriched in about 150 and $440 \mathrm{GO}$ terms in leaf and root tissues in DT, respectively, and about 13 and $70 \mathrm{GO}$ terms in DS, respectively. The top $30 \mathrm{GO}$ enrichment terms are displayed in Figures 1 and 2.

In addition, highly expressed and repressed $(|\log 2 \mathrm{FC}|>3)$ unique transcripts were assembled (Table S3), specifically in DT (Table S4). The abundance of expression of most DEGs was much higher in roots than in leaves. Four common transcripts upregulated between leaves and roots were selected: glutaredoxins, serine/threonine-protein kinase, a seed maturation protein, and one hypothetical protein. Nine commonly repressed transcripts were detected, including ERFs, brassinosteroid-regulated proteins, LRR receptors, putative receptor proteins, cytochrome $\mathrm{P} 450$ 94C1, and MYB-related proteins. The extent of the decrease of downregulated DEGs was much more in roots than in leaves. 

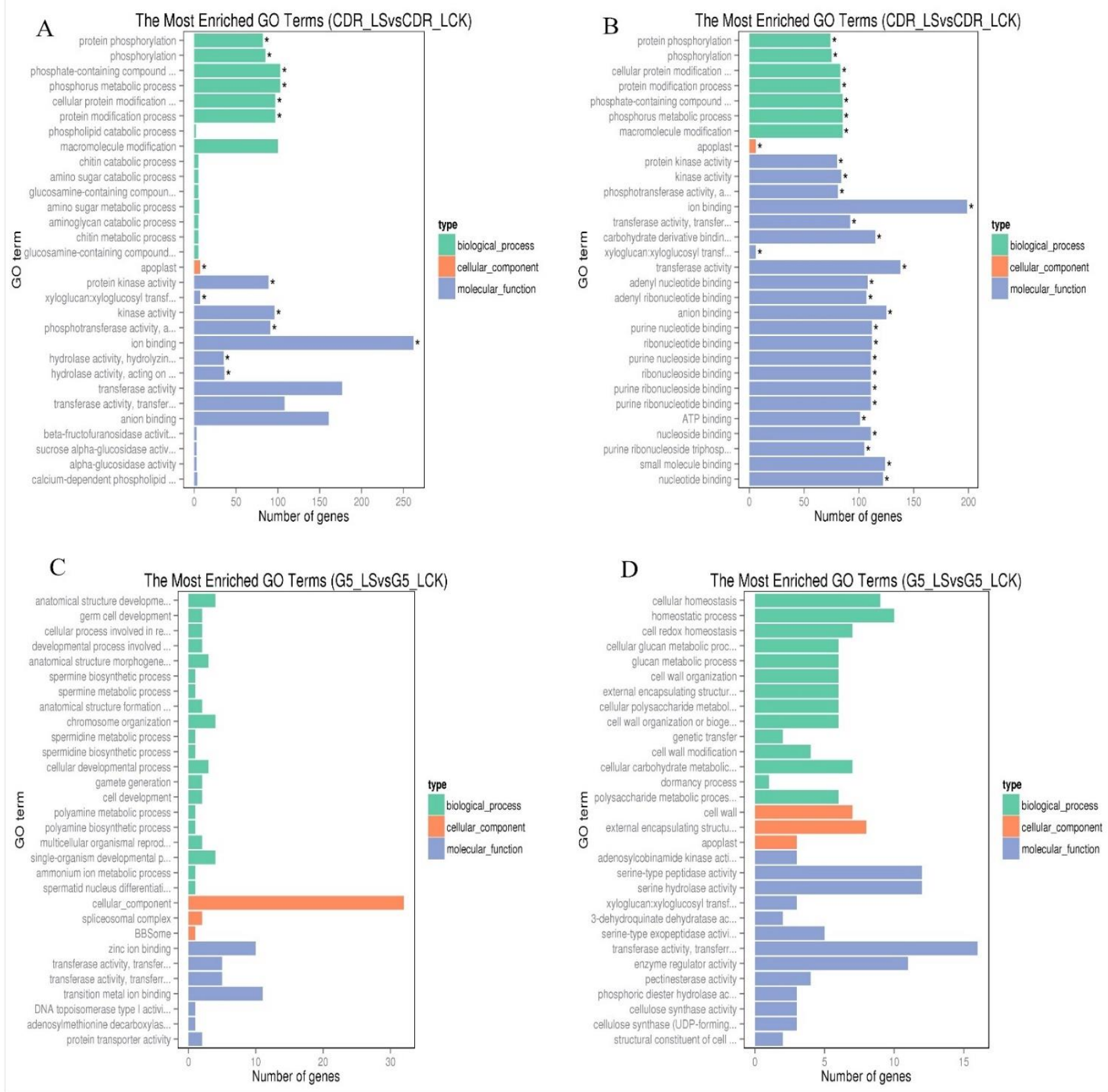

Figure 1. Functional annotation of drought-responsive genes upregulated and downregulated in CDR-1 and Gisela 5 leaves based on Gene Ontology (GO) categorization. (A) DEGs upregulated in CDR-1 leaves; (B) DEGs downregulated in CDR-1 leaves; (C) DEGs upregulated in Gisela 5 leaves; (D) DEGs downregulated in Gisela 5 leaves. Asterisks represent significantly enriched genes.

In DT, specific transcripts highly expressed in leaves included low-temperatureinduced protein, galactinol-sucrose galactosyltransferase, stachyose synthase-like, and so on. Specific repressed transcripts included dehydration-responsive protein RD22, alphatrehalose-phosphate synthase, receptor-like protein kinase, and so on (Table S4). Roots mainly involved TFs, translocator protein homologs, septum-promoting GTP-binding protein, late embryogenesis abundant protein, and sodium-potassium-calcium exchanger; repressed transcripts were related to $\mathrm{TFs}$, protein phosphatase $2 \mathrm{C}$, serine/threonine-protein kinase, disease resistance protein, and so on (Table S5). In DS, specific induced transcripts in leaves included protein phosphatase $2 \mathrm{C}$, zinc finger proteins, 2-aminoethanethiol dioxy- 
genase, and others (Table S6). In DS roots, the transcripts included TF NAC4, U-box domain-containing protein, protein phosphatase $2 \mathrm{C}$, and others (Table S7).
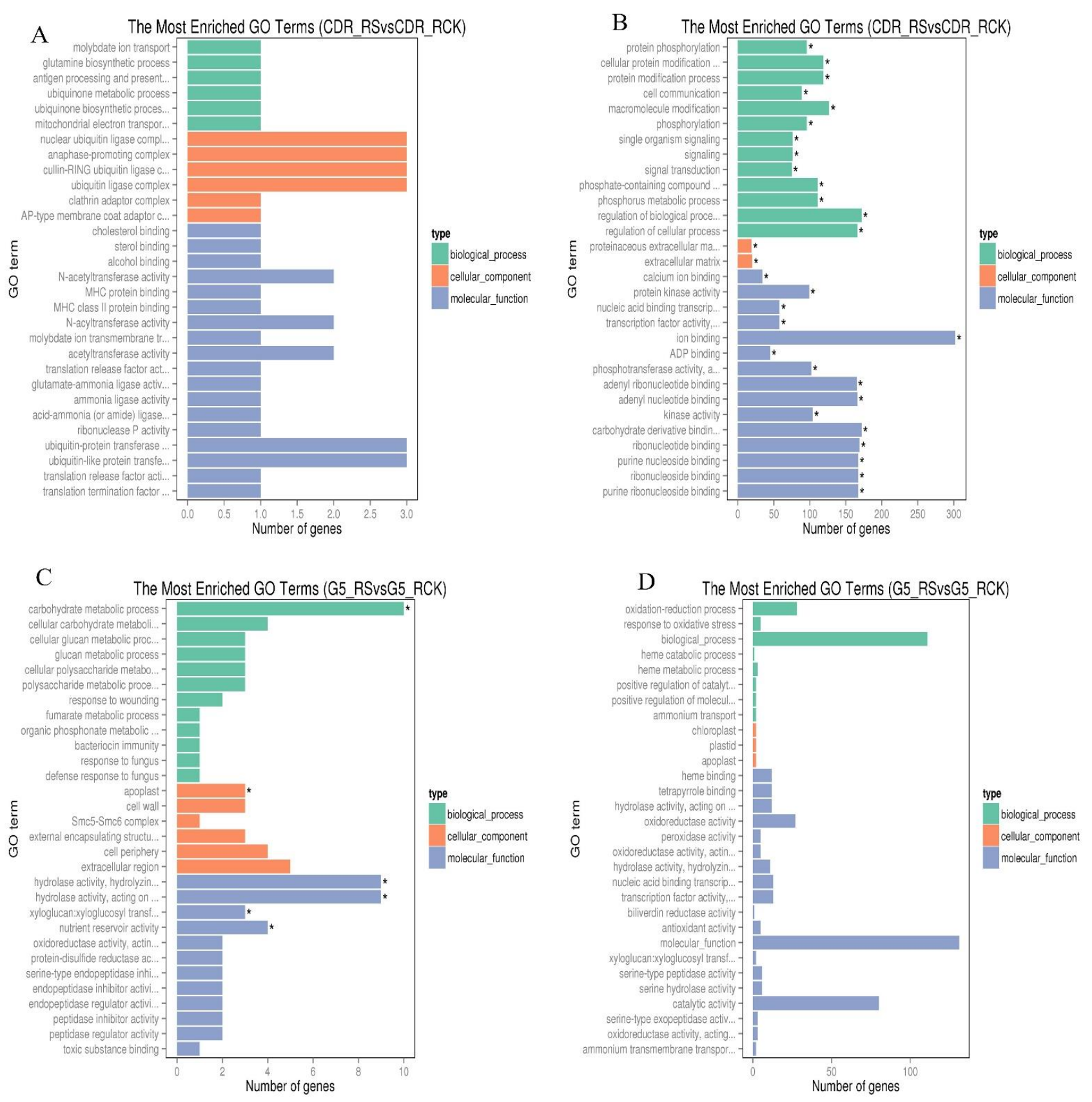

Figure 2. Functional annotation of drought-responsive genes up- and downregulated in CDR-1 and Gisela 5 root tips based on Gene Ontology (GO) categorization. (A) DEGs upregulated in CDR-1 roots; (B) DEGs downregulated in CDR-1 roots; (C) DEGs upregulated in Gisela 5 roots; (D) DEGs downregulated in Gisela 5 roots. Asterisks represent significantly enriched genes.

\subsection{Interaction Networks of DEGs between DT and DS}

DEG interaction networks were built to show the relationships between these genes in biological systems and to understand how these response genes interact with one another under drought stress. From upregulated DEGs in DT leaves, we obtained two interaction networks related to terpenoid biosynthesis and the regulation of plant circadian rhythm. In the first, solanesyl-diphosphate synthase interacted with RNA polymerase sigma factor, 
aarF domain-containing protein kinase, and ATP-dependent zinc metalloprotease FTSH 8 as part of terpenoid biosynthesis. In the second, PM-YC3.6-Lti6b interacted with DnaJ homolog subfamily B member 3, two-component response regulator-like APRR5, twocomponent response regulator-like APRR9, and adagio protein 3 as part of the regulation of the plant circadian rhythm in leaves (Figure 3).

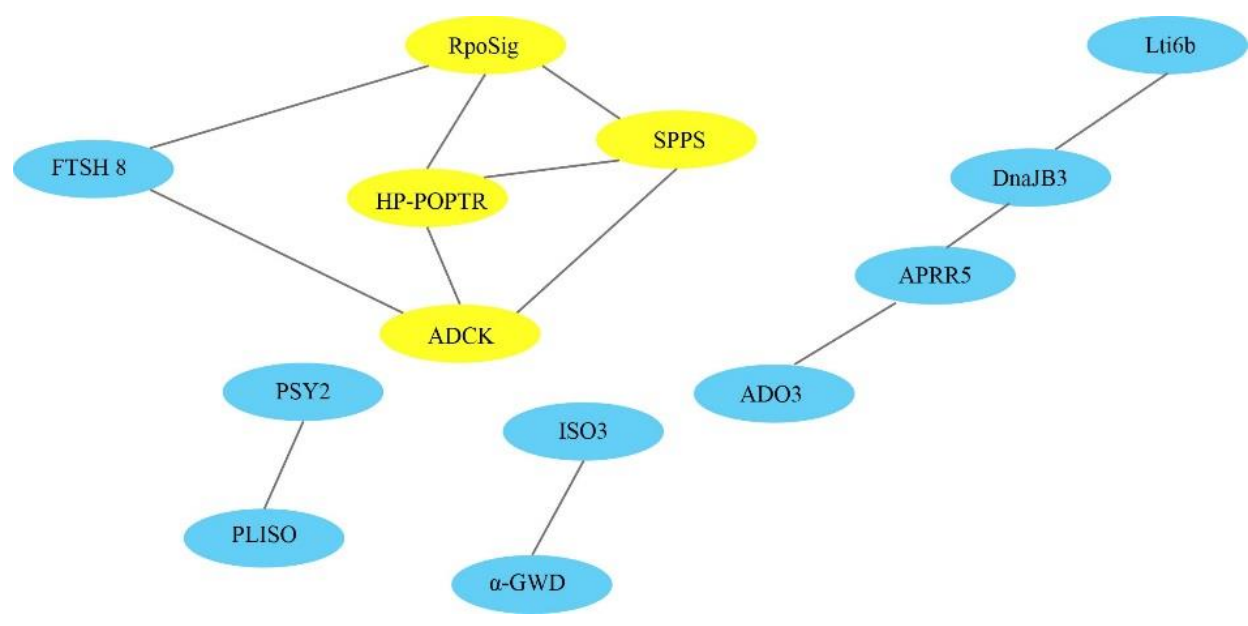

Figure 3. Interaction networks of upregulated DEGs in the drought-tolerant species CDR-1. Yellow ellipses show that genes interacted with at least three other genes. Blue ellipses show that genes interacted with fewer than three other genes. RpoSig, RNA polymerase sigma factor (AT5G24120.1); SPPS, solanesyl-diphosphate synthase (AT1G17050); HP-POPTR, hypothetical protein POPTR_0019s08420g (AT3G56290.1-P); ADCK, aarF domain-containing protein kinase (AT3G24190.1); FTSH 8, ATPdependent zinc metalloprotease FTSH 8 (AT1G06430.1); Lti6b, PM-YC3.6-Lti6b (AT3G05890.1); DnaJB3, DnaJ homolog subfamily B member 3 (AT1G56300.1); APRR5, two-component response regulator-like APRR5 (AT5G24470.1); ADO3, adagio protein 3 (AT1G68050.1); PSY2, phytoene synthase 2, chloroplastic-like (AT5G17230.3); PLISO, prolycopene isomerase, chloroplastic (AT1G57770.1); ISO3, isoamylase 3, chloroplastic (AT4G09020.1); $\alpha$-GWD, alpha-glucan water dikinase, chloroplastic (AT1G10760).

Moreover, downregulated transcripts in the DT leaves interacted intensively around plant hormone signal transduction, plant-pathogen interaction, starch and sucrose metabolism, linoleic acid, stilbenoid, diarylheptanoid, and gingerol metabolism. Downregulated transcripts in the DT roots interacted around vesicular transport, the biosynthesis of secondary metabolites, starch and sucrose metabolism, cysteine and methionine metabolism, RNA degradation, glycerophospholipid metabolism, linoleic acid metabolism, and amino sugar and nucleotide sugar metabolism. However, interaction among upregulated DEGs was not detected in our tests in either leaves or roots of the DS samples. However, ribosome biogenesis and starch, sucrose, amino sugar, and nucleotide sugar metabolism were obtained among downregulated DEGs in leaves, and cell energy metabolism was found among downregulated DEGs in roots.

To verify the reliability of the RNA-seq results, we randomly selected 10 DEGs, detected their expression by qRT-PCR, and compared the results to the RNA-seq data. Two upregulated DEGs (PAV_SC00001339.1_g2001.mk and PAV_SC0002493.1_g1001.mk) and eight downregulated DEGs (pav_SC0000893.1_g020.mk and others) were selected for qRT-PCR detection. The comparison showed that the RNA-seq expression was consistent with the qRT-PCR expression (Figure 4). 


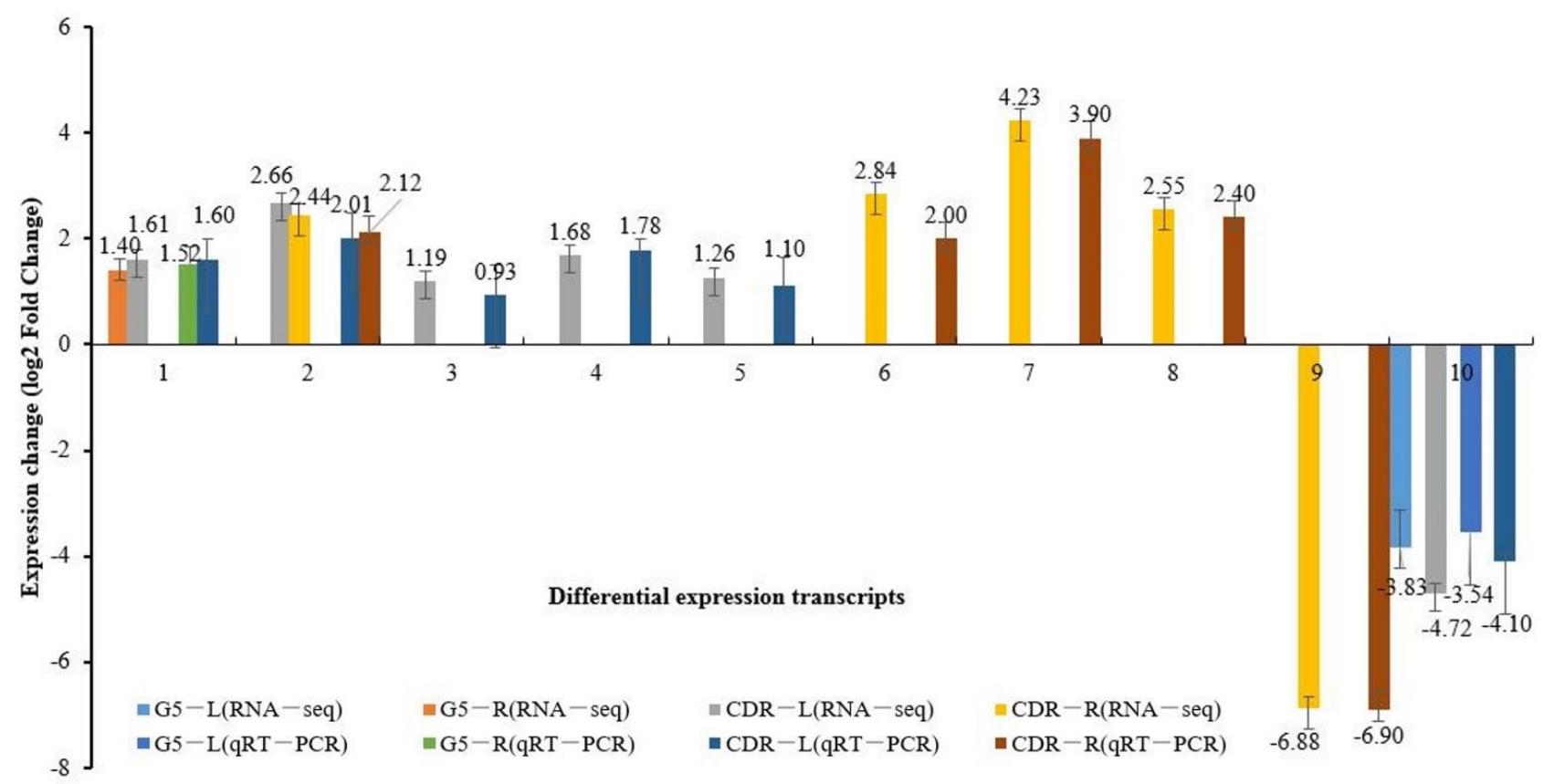

Figure 4. Changes in gene expression levels were confirmed using qRT-PCR. G5-L, leaves of Gisela 5; G5-R, root tissues of Gisela 5; CDR-L, leaves of Mahaleb CDR-1; CDR-R, root tissues of Mahaleb CDR-1. Transcripts ID: 1, Pav_sc0001339.1_g200.1.mk; 2, Pav_sc0002493.1_g100.1.mk; 3, Pav_sc0000131.1_g130.1.mk, 4, Pav_sc0000004.1_g040.1.mk; 5, Pav_sc0000311.1_g710.1.mk; 6, Pav_sc0000638.1_g820.1.mk; 7, Pav_sc0001335.1_g050.1.mk; 8, Pav_sc0001479.1_g020.1.mk; 9, Pav_sc0009842.1_g030.1.mk; 10, Pav_sc0000893.1_g020.1.mk.

\subsection{Metabolome Analysis and Screening of Central Metabolites}

From 24 test samples, namely, six quality controls in each group (Table 1), a total of 517 peaks were detected, and after data preprocessing, 461 effective peaks were evident (Figure S2). To compare differences in metabolic profiles among SG and CG, we first used PCA to visualize the impact of drought on the DT and DS metabolomes. A PCA model was created with four groups: QC (quality control samples), TOTAL (total samples), CCL-CSL (CG of DT leaves vs. SG of DT leaves), and GCL-GSL (CG of DS leaves vs. SG of DS leaves). The model showed the distribution of the origin data, and all sample data lay inside the $95 \%$ confidence region (Hotelling's $\mathrm{T}^{2}$ ellipse). The results indicated an obvious separation between the two genotypes and between SG and CG of CDR-1 (Figure S3A); no distinct boundary was observed between SG and CG of Gisela 5 (Figure S3C).

To obtain a higher level separation and a better understanding of the variables responsible for the classification, we then performed supervised OPLS-DA, which revealed the contributions of variables to the difference between the two groups and improved the classification. Finally, more satisfactory modeling and prediction results were obtained. Both SG and CG of the two genotypes were clearly separated from the control along PC1 (Figure S3B,D). The $\mathrm{R}^{2} Y$ and $\mathrm{Q}^{2}$ values were 0.997 and 0.767 in DT and 0.961 and 0.509 in DS, respectively (Table S8), which indicated that the metabolites of SG had changed significantly compared to CG in both genotypes.

\subsection{Identification and Cluster Analyses of Cherry Metabolites in Response to Drought}

Differentially expressed metabolites were selected based on OPLS-DA model VIP values $(>1)$ and significant changes between SG and CG (Student's $T$ test, $p<0.05$ ). A total of 234 differentially expressed metabolites were obtained in both genotypes, and 92 metabolites were upregulated. There were 14 common central metabolites in the two genotypes, including proline, asparagine, and quinic acid (Table 2), whose accumulations were generally higher than those of other metabolites. For example, 3-cyanoalanine increased by 4,111,229- and 2.1-fold in DT and DS, respectively. Moreover, 59 specific 
upregulated metabolites were detected in DT, including p-benzoquinone (p-BQ), melibiose, flavin adenine degrad product, salicin, serine, and citrulline (Table S9), which were mainly carbohydrate conjugated compounds, organic acids, and amino acids. A total of 19 specific upregulated metabolites were detected in DS, including maleic acid alanine, D-glyceric acid, and malonic acid (Table S10).

Table 2. Common central metabolites in cherry rootstocks.

\begin{tabular}{|c|c|c|c|c|c|c|c|c|c|c|}
\hline Metabolite & $\begin{array}{c}\text { Mean } \\
\text { CCL }\end{array}$ & $\begin{array}{c}\text { Mean } \\
\text { CSL }\end{array}$ & FC & VIP & $p$ & $\begin{array}{c}\text { Mean } \\
\text { GCL }\end{array}$ & $\begin{array}{c}\text { Mean } \\
\text { GSL }\end{array}$ & FC & VIP & $p$ \\
\hline Proline & 0.8516 & 0.9086 & 1.1 & 1.034 & 0.048 & 0.2199 & 0.4656 & 2.1 & 1.096 & 0.042 \\
\hline Asparagine & 0.0321 & 0.2258 & 7.0 & 1.141 & 0.049 & 0.1021 & 0.2609 & 2.6 & 1.273 & 0.022 \\
\hline Quinic acid & 0.0005 & 0.0985 & 182.6 & 2.381 & 0.031 & 0.1715 & 0.2519 & 1.5 & 1.282 & 0.048 \\
\hline Purine riboside & 0.0196 & 0.0785 & 4.0 & 1.228 & 0.039 & 0.1414 & 0.1594 & 1.1 & 1.333 & 0.028 \\
\hline Glutamine & 0.0349 & 0.1036 & 3.0 & 1.416 & 0.014 & 0.0111 & 0.0917 & 8.3 & 1.085 & 0.010 \\
\hline 3-cyanoalanine & $8.5523 \times 10^{-9}$ & 0.0352 & $4,111,229.0$ & 2.902 & 0.012 & 0.0141 & 0.0292 & 2.1 & 1.032 & 0.028 \\
\hline L-allothreonine & 0.0130 & 0.0245 & 1.9 & 1.358 & 0.014 & 0.0114 & 0.0206 & 1.8 & 1.233 & 0.026 \\
\hline Phenylalanine & 0.0110 & 0.0146 & 1.3 & 1.165 & 0.040 & 0.0090 & 0.0109 & 1.2 & 1.080 & 0.049 \\
\hline Fucose & 0.0045 & 0.0075 & 1.7 & 1.519 & 0.027 & 0.0049 & 0.0079 & 1.6 & 1.567 & 0.046 \\
\hline Salicylic acid & 0.0037 & 0.0059 & 1.6 & 1.000 & 0.027 & 0.0040 & 0.0074 & 1.8 & 1.264 & 0.008 \\
\hline Sulfuric acid & 0.0035 & 0.0056 & 1.6 & 1.000 & 0.032 & 0.0028 & 0.0060 & 2.2 & 1.081 & 0.006 \\
\hline Phytosphingosine & 0.0016 & 0.0118 & 7.3 & 1.295 & 0.044 & 0.0216 & 0.0359 & 1.7 & 1.085 & 0.032 \\
\hline Biotin & 0.0013 & 0.0002 & 0.2 & 1.032 & 0.047 & 0.0001 & 0.0002 & 2.0 & 1.021 & 0.048 \\
\hline D-glucoheptose & 0.0016 & 0.0033 & 2.1 & 1.565 & 0.031 & 0.0010 & 0.0042 & 4.4 & 1.256 & 0.000 \\
\hline
\end{tabular}

Common central metabolites here refer specifically to upregulated metabolites. GSL and GCL represent the drought stress treatment group and control group of Gisela 5 leaves; CSL and CCL represent the drought stress treatment group and control group of CDR-1 leaves. FC (fold change) indicates the ratio of the peak amount of drought stress groups (GSL, CSL) and the peak amount of control groups (GCL, $\mathrm{CCL}$ ). Differences are significant at $p<0.05$. Because the relative content of substances was detected by nontarget GC-MS, there are no units.

\subsection{Analysis of Metabolic Pathways and DEGs}

Differentially expressed metabolites and DEGs were mapped together into the KEGG database to mine candidate genes, associated with the enrichment of central metabolites, in the same metabolic pathways. Eight amino acids, 16 organic acids, and other secondary metabolites and related genes were enriched in 16 metabolic pathways, including cyanoamino acid metabolism and phenylpropanoid biosynthesis (Table S11).

Cyanoamino acid metabolism was the most notable pathway that enriched 3-cyanoalanine, phenylalanine, asparagine, glycine, serine, alanine, valine, and isoleucine (Figure S4). 3-cyanoalanine, phenylalanine, and asparagine were the common central metabolites in both genotypes, but with great differences in the amounts of their increases. Serine and glycine were specifically upregulated in DT and interacted directly in this pathway. In contrast, alanine, valine, and isoleucine were specifically upregulated in DS (Figure S4). The genes involved in cyanoamino acid metabolism in DT were three $\beta$-glucosidase genes, one amygdalin hydrolase precursor gene, one amino acid transferase gene, and one mannitol lyase gene. Those in DS were one $\beta$-glucosidase gene and several genes encoding unknown functional proteins (Table S11).

The phenylpropanoid biosynthesis pathway was related to quinic acid, citric acid, 4-hydroxy-3-methoxycinnamaldehyde, and chlorogenic acid. Quinic acid was upstream and phenylalanine was downstream. Chlorogenic acid hydrolysis produced quinic acid and caffeic acid (reaction ID: RO299). Chlorogenic acid (reaction ID: RO194) was produced by quinic acid and caffeoyl-coenzyme A (CoA), whereas caffeoyl-CoA was produced by caffeic acid, ATP, and CoA. Quinic acid, chlorogenic acid, and caffeic acid were upregulated and specifically accumulated in DS (Figure S5). In DT, quinic acid, phenylalanine, and pcoumaric acid increased significantly, and from upstream to downstream there was quinic acid, phenylalanine, and p-coumaric acid. In the phenylpropanoid biosynthesis pathway, the upregulated DEGs were mainly coumarin-CoA ligase, $\beta$-glucoside enzyme, and laetrile hydrolase precursor genes in DT and the $\beta$-glucoside enzyme gene and peroxidase genes in DS (Table S11). 


\subsection{Selection of Core Candidate Genes}

Key pathways and candidate genes were acquired by GO analysis, KEGG analysis, and interaction analysis of protein-protein interaction networks of DEGs. After conjoint analysis of central metabolites, we focused on upregulated genes involved in differential metabolites or metabolic pathways (Table S11), such $\beta$-glucosidase, 4-coumarate-CoA ligase and so on. A total of 17 DEGs were selected as core candidate genes with high abundance, significant differences, and participation in several important metabolic pathways. Among them, four genes were involved in energy metabolism: $\beta$-amylase, $\beta$-glucosidase, ATPbinding cassette transporter $\mathrm{G}$ family member 22 and sugar transporter ERD6-like 16. The $\beta$-glucosidase gene was involved in many metabolic pathways, such as cyanoalanine metabolism and phenylpropane synthesis, and encoded a protein with 508 amino acids (Table 3). In addition, three ubiquitin ligase genes (E3 ubiquitin-protein ligase, protein gene with U-box, and protein gene with F-box) were selected with specific upregulation in DS. One TF involved in the drought response was screened, namely, zinc finger protein gene. It was upregulated and differentially expressed in leaves and root tips in DT and downregulated in leaves in DS; it was not expressed in roots in DS. The zinc finger gene was predicted to encode a protein with 111 amino acids, and subcellular localization was predicted in the nucleus, extracellular membrane, and chloroplasts (Table 3).

Table 3. Biological information on core candidate genes in the responses of cherry rootstocks to drought.

\begin{tabular}{|c|c|c|c|c|}
\hline Gene ID & Putative Function & $\begin{array}{l}\text { Number of } \\
\text { Amino Acids }\end{array}$ & Theoretical pI & $\begin{array}{l}\text { Putative Subcellular } \\
\text { Localization }\end{array}$ \\
\hline Pav_sc0006061.1_g110.1.mk & $\begin{array}{l}\text { Beta-amylase } 3 \text {, chloroplastic } \\
\text { [Prunus avium] }\end{array}$ & 547 & 9.01 & $\begin{array}{l}\text { Chloroplasts, nucleus, } \\
\text { mitochondria }\end{array}$ \\
\hline Pav_sc0005750.1_g010.1.br & Beta-glucosidase 11-like & 508 & 6.25 & $\begin{array}{l}\text { Vacuole, chloroplasts, } \\
\text { extracellular membrane }\end{array}$ \\
\hline Pav_sc0000004.1_g040.1.mk & $\begin{array}{l}\text { ABC transporter G family } \\
\text { member 22-like isoform X3 } \\
{[\text { Prunus avium] }}\end{array}$ & 603 & 8.23 & $\begin{array}{l}\text { Plasma membrane, } \\
\text { vacuole }\end{array}$ \\
\hline Pav_sc0004467.1_g120.1.mk & Sugar transporter ERD6-like 16 & 376 & 6.84 & $\begin{array}{l}\text { Plasma membrane, } \\
\text { nucleus }\end{array}$ \\
\hline Pav_sc0000491.1_g270.1.mk & $\begin{array}{l}\text { Stachyose synthase-like, } \\
\text { raffinose synthase or seed } \\
\text { imbibition protein }\end{array}$ & 867 & 5.66 & $\begin{array}{l}\text { Chloroplasts, } \\
\text { cytoplasm, and nucleus }\end{array}$ \\
\hline Pav_sc0001335.1_g550.1.mk & $\begin{array}{l}\text { RNA polymerase sigma factor } \\
\text { sigE, } \\
\text { chloroplastic/mitochondrial } \\
\text { [Prunus avium] }\end{array}$ & 550 & 10.00 & $\begin{array}{l}\text { Nucleus, chloroplasts, } \\
\text { nucleus, mitochondria }\end{array}$ \\
\hline Pav_sc0002893.1_g310.1.mk & $\begin{array}{l}\text { Alpha-glucan water dikinase, } \\
\text { chloroplastic isoform } \mathrm{X} 1 \\
\text { [Glycine max] }\end{array}$ & 1468 & 6.40 & Chloroplasts \\
\hline Pav_sc0001335.1_g050.1.mk & $\begin{array}{l}\text { Probable protein phosphatase } \\
2 C 51\end{array}$ & 395 & 7.62 & $\begin{array}{l}\text { Chloroplasts, nucleus, } \\
\text { and cytoplasm }\end{array}$ \\
\hline Pav_sc0001405.1_g970.1.mk & $\begin{array}{l}\text { Temperature-induced } \\
\text { lipocalin-1 [Prunus avium] }\end{array}$ & 185 & 5.97 & Nucleus and cytoplasm \\
\hline Pav_sc0002493.1_g100.1.mk & $\begin{array}{l}\text { Early light-induced protein } 1 \text {, } \\
\text { chloroplastic-like } \\
\text { [Prunus avium] }\end{array}$ & 94 & 10.16 & Chloroplasts, nucleus \\
\hline Pav_sc0000138.1_g610.1.mk & $\begin{array}{l}\text { Two-component response } \\
\text { regulator-like APRR } 5\end{array}$ & 691 & 5.96 & Nucleus \\
\hline
\end{tabular}


Table 3. Cont.

\begin{tabular}{|c|c|c|c|c|}
\hline Gene ID & Putative Function & $\begin{array}{c}\text { Number of Amino } \\
\text { Acids }\end{array}$ & Theoretical pI & $\begin{array}{l}\text { Putative Subcellular } \\
\text { Localization }\end{array}$ \\
\hline Pav_sc0001305.1_g820.1.mk & $\begin{array}{l}\text { Late embryogenesis } \\
\text { abundant protein 1-like }\end{array}$ & 164 & 9.40 & $\begin{array}{l}\text { Mitochondria, } \\
\text { chloroplasts, cytoplasm }\end{array}$ \\
\hline Pav_sc0000719.1_g800.1.mk & $\begin{array}{l}\text { E3 ubiquitin-protein } \\
\text { ligase At } 4 \mathrm{~g} 11680 \\
\text { isoform X1 }\end{array}$ & 330 & 8.94 & $\begin{array}{l}\text { Plasma membrane, } \\
\text { vacuole, endoplasmic } \\
\text { reticulum, and Golgi } \\
\text { apparatus }\end{array}$ \\
\hline Pav_sc0000464.1_g820.1.mk & $\begin{array}{l}\text { U-box } \\
\text { domain-containing } \\
\text { protein } 4\end{array}$ & 383 & 6.03 & Nucleus, cytoplasm \\
\hline Pav_sc0000067.1_g380.1.mk & $\begin{array}{l}\text { F-box/LRR-repeat } \\
\text { MAX2 homolog A-like }\end{array}$ & 654 & 5.86 & Nucleus, cytoplasm \\
\hline Pav_sc0000586.1_g780.1.mk & $\begin{array}{l}\text { Homeobox-leucine } \\
\text { zipper protein } \\
\text { ATHB-12-like }\end{array}$ & 322 & 4.58 & Nucleus \\
\hline Pav_sc0004290.1_g270.1.mk & $\begin{array}{l}\text { Zinc finger } \mathrm{CCCH} \\
\text { domain-containing } \\
\text { protein 23-like [Prunus } \\
\text { avium] }\end{array}$ & 111 & 4.60 & $\begin{array}{l}\text { Nucleus, chloroplasts, } \\
\text { extracellular membrane }\end{array}$ \\
\hline
\end{tabular}

Note: The most likely located organelle is ranked first; possibility is ranked from high to low.

\section{Discussion}

We used metabolomic and transcriptomic analyses to analyze metabolites and related genes involved in the drought response of two contrasting cherry rootstocks, $P$. mahaleb CDR-1 and P. cerasus $\times$ P. canescens Gisela $5[11,12]$. When cherry rootstocks were exposed to severe drought, a large number of genes were downregulated, and relatively fewer genes were upregulated (Figure S3). This may be due to a decrease in metabolic activity following the stress. Phytohormones regulate plant response to drought stress by integrating external stimuli with complex regulatory networks. In this study, a large number of hormonerelated genes were significantly upregulated or downregulated in the roots and leaves of the two cherry rootstocks after exposure to drought. The plant hormone pathways involved in regulation included the abscisic acid, ethylene, cytokinin, salicylic acid, brassinosteroid, and jasmonic acid signaling pathways, which were mainly focused on DT in our previous studies [31]. In contrast, upregulated genes and upregulated metabolites are likely closely related to improvement in plant resistance and survival and correspond to the increased activity of soluble sugar, proline, and peroxidase in the physiological response [32-35], which was also a focus of this study.

Under water deficit, the plants' metabolic balance is readjusted and metabolic responses to drought stress in plants have attracted more attention. Ferulic acid was reported to provide protection to photosynthesis during drought stress [36], and 4-hydroxycinnamic acid and ferulic acid were considered as key metabolites for rice drought-tolerance [37]. We identified six central metabolites-3-cyanoalanine, phenylalanine, quinic acid, asparagine, p-benzoquinone, and phytosphingosine as potential biological markers of the drought response in cherries. Moreover, metabolites involved in plant stress response-the accumulation of sugar (such as fructan) or amino acids (such as proline)-serve as osmoprotectant under drought stress [21]. In this study, a large number of organic acids were correlated with drought resistance and we divided them into three groups.

The first group included most amino acids: asparagine, arginine, cysteine, glycine, serine, alanine, valine, isoleucine, and so on. These amino acids play key roles in regulating cell osmosis, reducing active oxygen damage, and keeping enzymes and proteins stable [38-40]. Asparagine, a nitrogen-transportable amino acid in plants that is associated 
with resistance to disease and adversity, accumulated in large amounts in both genotypes. Asparagine synthase genes improve stress resistance [41,42]. However, serine and glycine accumulated specifically in DT, whereas alanine, valine, and isoleucine accumulated specifically in DS (Figure S4). In both genotypes, different amino acids accumulated under drought stress, as mentioned above.

The second group, proline and linolenic acid have been reported widely in plant abiotic stress responses as regulation compounds. The proline biosynthesis gene P5CS was upregulated in both genotypes. Linolenic acid accumulated in DT as the main ingredient in galactolipid. Linolenic acid belongs to the cell membrane lipids and is involved in responses to multiple stresses, such as drought, cold, and high temperature [43-46]. It increased in the drought-tolerant cultivar, in accordance with a study on grape seedlings under drought stress [47]. However, linolenic acid remained relatively unchanged in the drought-susceptible cultivar. It may work as a regulation lipid on the cell membrane to reduce the damage caused by drought stress.

The third group included cyanoalanine, phenylalanine, quinic acid, coumaric acid, citric acid, caffeic acid, chlorogenic acid, and others. Cyanoalanine, phenylalanine, and quinic acid were common central response metabolites in DT and DS. Cyanoalanine synthase can convert toxic cyanide into nontoxic cyanide alanine and further into asparagine in plants $[48,49]$. Cyanoalanine derivatives are generated by HCN conjugates, being a coproduct of ethylene synthesis [50]. Cyanoalanine increased by million folds in DT under water deficit but was almost undetectable in the well-watered treatment. In contrast, it increased 1.5 times in DS. This result is in keeping with research on Caragana korshinskii, in which cyanoalanine increased 6.9 times under drought stress [51]. Cyanoalanine may be the product of cyanide detoxification. At the same time, we found that asparagine, its downstream product, increased 7.0 and 2.6 times in DT and DS, respectively. This further confirms that cyanide turns into a harmless substance after detoxification and synthesizes into metabolites that are beneficial to plant growth. The detoxification of cyanide was more efficient in DT than in DS; in other words, the former suffered less under the same drought conditions. The efficiency of detoxification to avoid cell damage under drought stress is an important factor in determining drought resistance. However, cyanoalanine synthase genes could not be screened in this work, as they may have been triggered and expressed at an earlier period.

The synthesis of phenylalanine was more efficient in DT than in DS under drought stress. However, reports of the role of phenylalanine in the drought response are mixed. Consistent with this study, phenylalanine increased in potatoes [52]; however, it decreased in chickpeas [53]. This phenomenon may be related to plant species, duration of stress, or stress level. As an upstream compound of the phenylalanine synthesis pathway, quinic acid is also a precursor to lignin synthesis [54] and increased million folds in DT but only 1.5 times in DS. This result is in accordance with reports on Oleaceae trees [55] but is opposite to findings on peaches, in which it decreased [56]. Quinic acid is involved in the resistance of plant cells to oxidation [57] and can improve plant resistance to strong light and high temperature $[58,59]$. These findings suggest that phenylalanine and quinic acid are closely related to plant response to drought or stress, but the response mechanisms need to be verified further. In addition, p-coumaric acid increased significantly in DT. Downstream of phenylalanine and quinic acid, it might also be related to cherry response to drought. However, caffeic acid and chlorogenic acid were specifically induced in DS (Figure S5). Plants produce cyanide under stress, and the accumulation of cyanide can be toxic to plant cells, although plants themselves have detoxification systems to reduce this damage.

According to these findings, the common pathway between DT and DS was quinic acid $\rightarrow$ phenylalanine $\rightarrow$ cyanoalanine $\rightarrow$ asparagine, but the efficiency of the synthesis of quinic acid, cyanoalanine, and asparagine differed (Table 2). First, DT was significantly higher than Gisela 5, especially cyanoalanine. Second, there may have been a difference in the response pathways. In DT the pathway was quinic acid $\rightarrow$ phenylalanine $\rightarrow$ p-coumaric 
acid, whereas in DS it was more likely to be quinic acid $\rightarrow$ coffeic acid $\rightarrow$ chlorogenic acid (Figure 5). The main factors contributing to the difference were p-coumaric acid, coffeic acid, chlorogenic acid, and other specific metabolites, such as serine and glycine in DT and alanine, valine, and isoleucine in DS.

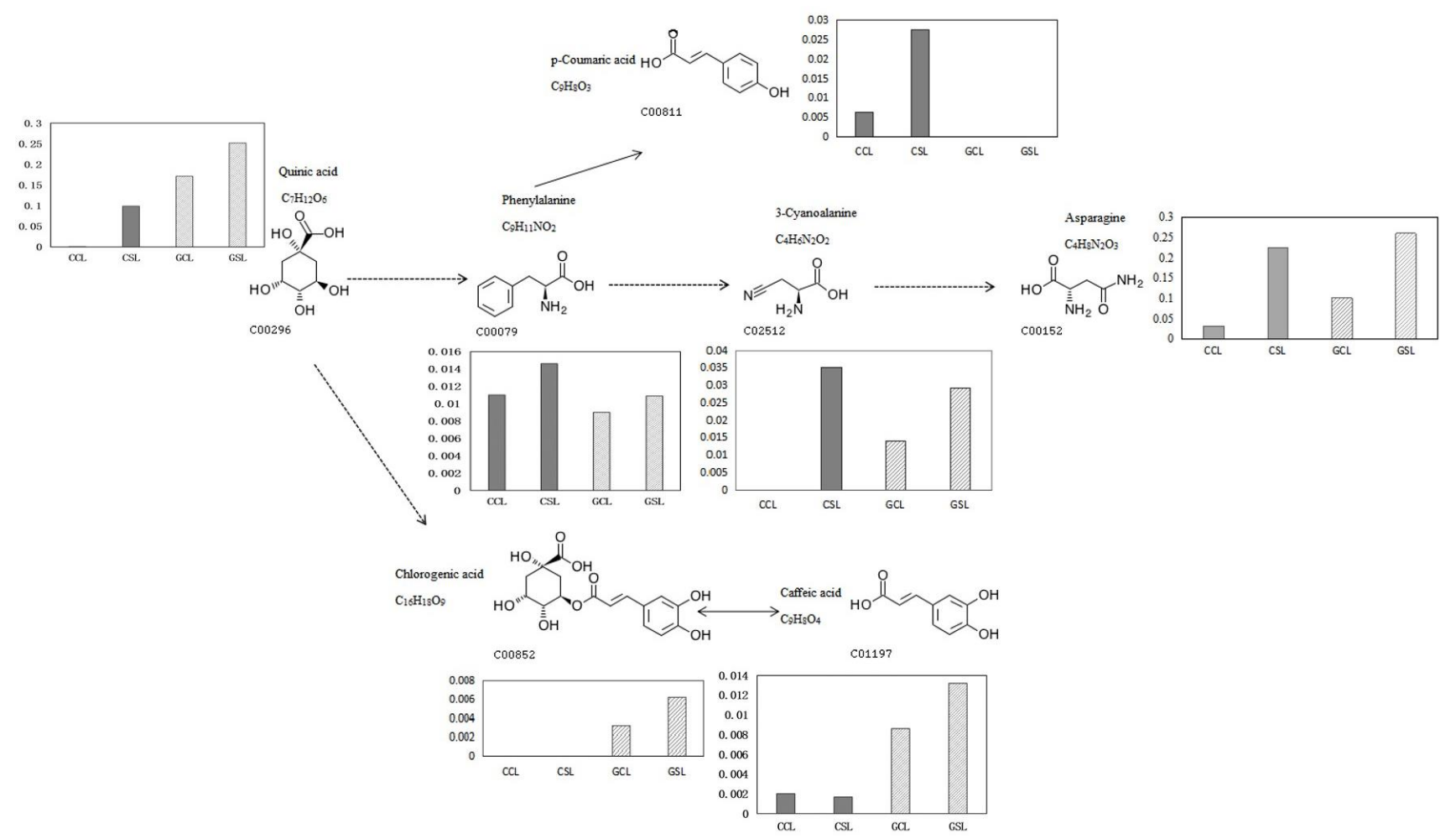

Figure 5. The pathway diagram of key drought-responsive metabolites from two cherry rootstocks. Solid arrows indicate direct reactions between metabolites. Dashed arrows indicate indirect reactions between metabolites. CCL and CSL represent control and drought treatment samples of CDR-1. GCL and GSL represent control and drought treatment samples of Gisela 5. Because the relative content of substances was detected by nontarget GC-MS, there are no units.

Furthermore, in DT, the most induced metabolites also included 2,3-dimethyl succinic acid, maleamate, and phytosphingosine. Many derivatives of succinic acid have been proposed as regulators of plant growth and herbicides, and 2,3-dimethyl succinic acid is one. They act as signaling compounds to integrate energetic metabolism and the hormonal systems of plants [60]. Succinic acid preparations can increase plant resistance to unfavorable conditions (drought, cold, etc.), which is helpful in protecting plants from frost, decreasing infection, and enhancing the chlorophyll content of leaves [61]. There are limited reports of maleamate in plant metabolism. Ethyl N (3,4-dichlorophenyl) maleamate acts as an inhibitor or suppressor of crabgrass [62], although little is known about the role of maleamate in plants.

Moreover, genes related to lipid synthesis and transport were upregulated in DT leaves, whereas genes involved in lipid metabolism were upregulated in roots and leaves. Sphingolipids (SPLs), a diverse group of lipids, are present in all eukaryotes. The main SPL in plants is phytosphingosine, which can inhibit cell growth and nutrient transport [63] and respond to plant diseases [64]. SPLs are dynamic regulators of plant cellular processes and are essential for basic cellular functions, cell tissue, and motility [65]. Phytosphingosine increased significantly under drought treatment in DT, and thus could be used as a marker metabolite. Moreover, functional analysis of SPL biosynthesis demonstrated that these lipids were directly involved in many aspects of plant development and response to environmental changes, including biotic and abiotic stimuli. The modification of lipid composition differed in drought-tolerant and drought-susceptible plants under stress, 
which suggests that lipid composition is of great significance to the drought resistance of plants. However, the specific role of plant secondary metabolites in enhancing drought resistance is not fully understood and needs to be explored further [66]. According to DT transcriptome analysis, glycogen biosynthesis and glycosyl hydrolase genes were downregulated to rebuild energy homeostasis, NCED homology genes were induced for stomatal regulation and water conservation, expression of linolenic acid and amino acid synthesis genes was generally increased to enhance drought tolerance, and TFs (CBF/NFYs, MYB, WRKY and U-box) may regulate key functional genes to adapt to stress, as reported in our previous research [31].

Finally, when we combined metabolomic analysis with transcript analysis, we detected proline, aspartate, and glutamate metabolism; purine metabolism; and galactose metabolism as common biological responses to coping with drought in both cherry rootstocks. According to the interaction analysis of differentially expressed metabolites, the main metabolites (Figure 6) were mapped into seven pathways: tricarboxylic acid (TCA) cycle; arginine metabolism; proline, glutamate, and asparagine metabolism; and other metabolism (Figure S6). However, in DS, D-glucoheptose tagatose, 2-deoxyerythritol, and 1-aminocyclopropanecarboxylic acid increased significantly. Differentially expressed metabolites also included tagatose, 4-aminobutyric acid, citrulline, and xanthine in DS (Figure 6), which were involved in mutual interaction pathways (Figure S7). In most studies, organic acids and TCA cycle intermediates increase in response to drought stress or temperature but decrease in glycophytes after salt stress [67]. Among carbonyl compounds, $\mathrm{p}-\mathrm{BQ}$ and maltotriose, except 3-cyanoalanine, increased significantly in DT. As the electron acceptor in PS II activity, p-BQ increases dramatically after drought, whereas main proteins and elements involved in photosynthesis are repressed under water deficiency [68]. p-BQ may play a crucial role in maintaining photosynthetic capacity; however, there is limited information on this response. As carbohydrate conjugates, maltotriose with glucose, sucrose, galactose, fructan, and trehalose were reported to be involved in plant abiotic stress responses $[67,69,70]$. Sugars not only represent an energy source but also are precursors to carbon, substrates for polymers, storage and transport compounds, and signaling molecules.

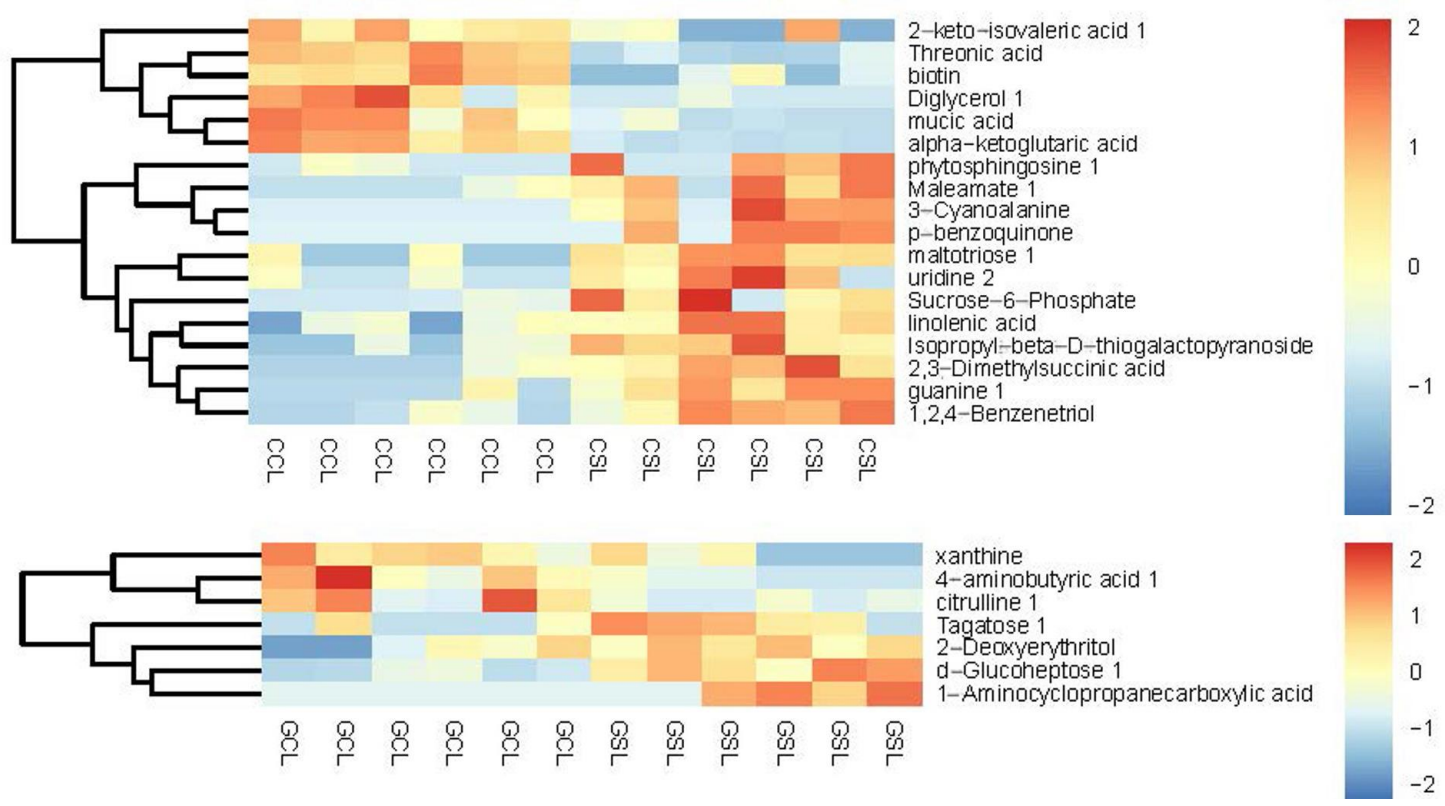

Figure 6. Heat map of the hierarchical clustering analysis of CDR-1 (CCL, CSL) and Gisela 5 (GCL, GSL). CCL, CSL, GSL, and GCL are the same as in Figure 4. Increasing and decreasing contents of metabolites are shown in orange and blue, respectively. 


\section{Conclusions}

We comprehensively analyzed overall changes in metabolic profiles in two contrasting cherry rootstocks and also performed transcript analysis. The results focused on the TCA cycle, energy metabolism, and lipid metabolism pathways, which were strongly relevant in DT and DS. Central metabolites and DEGs related to the cyanoalanine and phenylpropane metabolism pathways were the key factors in the difference in drought resistance of DT and DS. The drought-tolerant cherry appears to adapt to water deficits by expressing constitutively high levels of some protective metabolites, such as quinic acid and asparagine, and some specific metabolites, such as serine and glycine, in DT. Moreover, we explored 17 core candidate genes (Table 3) and screened six, including candidate metabolitequinic acid, phytosphingosine, 3-cyanoalanine, $\mathrm{p}-\mathrm{BQ}$, and phenylalanine. Combining transcriptional and physiological results for DT [31], we created a deductive diagram of drought regulation mechanisms to describe and understand the drought regulation process of the drought-tolerant rootstock P. mahaleb CDR-1 (Figure 7). The metabolic pathways identified, functional validation of drought-responsive genes, and drought regulation mechanisms deduced in this study help uncover the complexity of drought tolerance at the molecular level and will be useful for breeding drought-tolerant cherry cultivars.

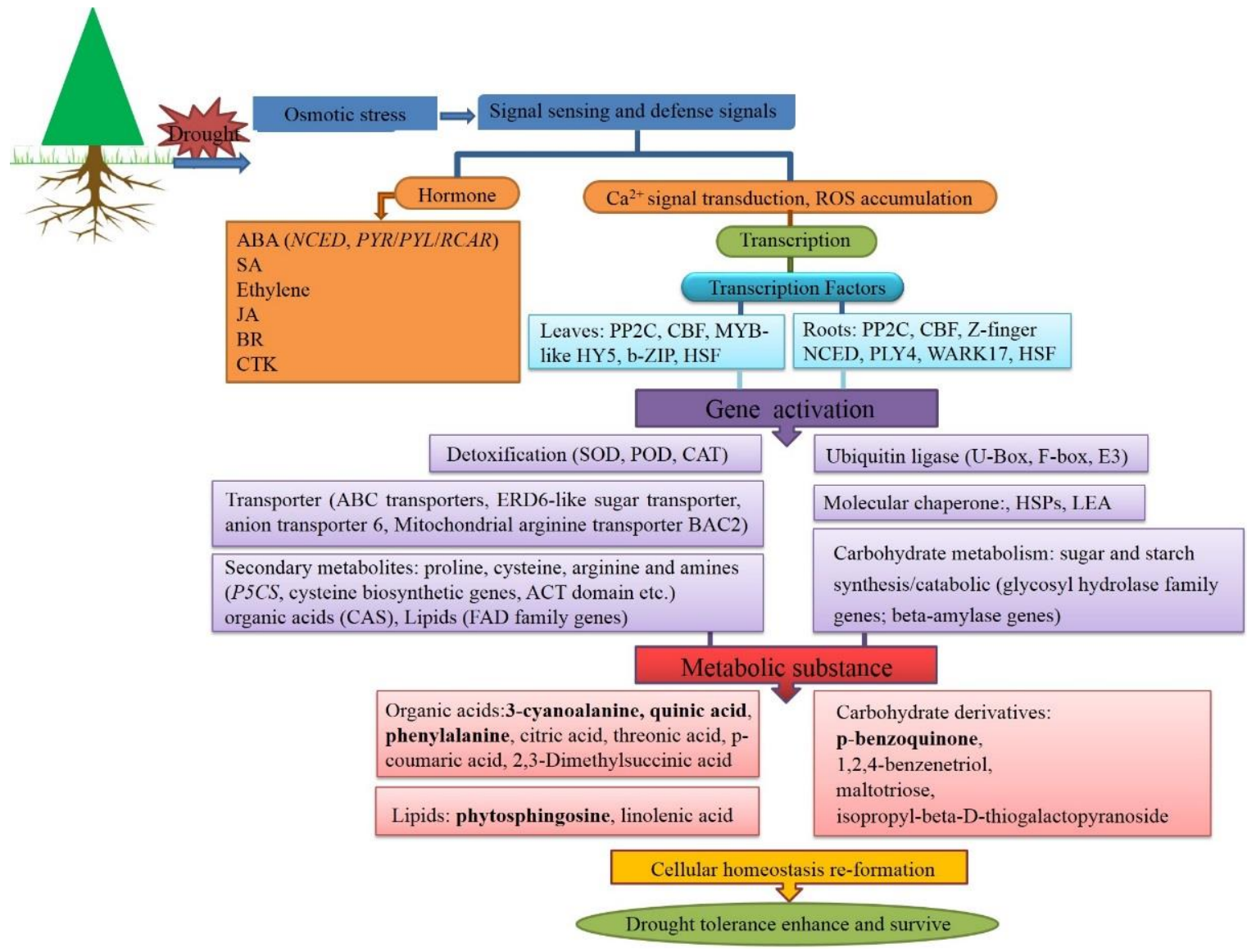

Figure 7. Deductive diagram of the drought-tolerant cherry rootstock P. mahaleb CDR-1.

Supplementary Materials: The following are available online at https:/ / www.mdpi.com/2079-773 7/10/3/201/s1, Table S1: Primers used for the quantitative real-time PCR. Table S2: Transcriptome Illumina sequencing and mapped results for CDR-1 and Gisela 5. Table S3: Common transcripts involved in the drought response in CDR-1 and Gisela 5 leaves and roots. Table S4: Highly induced and repressed transcripts unique to CDR-1. Table S5: Highly induced and repressed transcripts unique to CDR-1. Table S6: Highly induced and repressed transcripts unique to Gisela 5 leaves. Table S7: Highly induced and repressed transcripts unique to Gisela 5 roots. Table S8: Explanation and pre- 
dictability of the principal component analysis (PCA) and partial least squares-discriminant analysis (PLS-DA). Table S9 Differential drought responded upregulated metabolites in CDR-1. Table S10 Differential drought responded upregulated metabolites in Gisela 5. Table S11 Candidate DEGs involved in KEGG pathways that are related to differential metabolites. Figure S1: Venn diagrams of genes significantly differentially expressed between drought and well-watered treatments in CDR-1 and Gisela 5 roots and leaves. Figure S2: GC-TOFMS ion chromatogram of all samples. Figure S3: PCA model and OPLS-DA model score scatter plot for CDR-1 and Gisela 5 drought-responsive differential metabolites. Figure S4: Drought-responsive metabolites and genes in cherry rootstocks involved in the cyanoamino acid metabolism pathway. Figure S5: Drought-responsive metabolites and genes in cherry rootstocks involved in the phenylpropanoid biosynthesis pathway. Figure S6: Interaction analysis of differentially expressed metabolites in CDR-1. Figure S7: Interaction analysis of differentially expressed metabolites in Gisela 5.

Author Contributions: Y.C. and L.H. conceived the project; Y.C. and Y.F. designed the experiments; T.W. and Y.F. performed experiments, analyzed data and wrote the first manuscript; T.W. and C.L. prepared the experimental materials; C.L. and L.P. contributed with editing the manuscript and coordinated the project. All authors have read and agreed to the published version of the manuscript.

Funding: This work was financially supported by the Key Research and Development Projects of Shaanxi Province (No. 2020ZDLNY01-05) and the Science and Technology Plan Projects of Shaanxi Province (Grant number 2019NY-011). The supporters had no role in study design, data collection, data analysis, data interpretation, the writing of the manuscript or decision to publish.

Institutional Review Board Statement: Not applicable.

Informed Consent Statement: Not applicable.

Data Availability Statement: The sequencing raw data for 24 samples can be accessed in the NCBI Sequence Read Archive (SRA) database under the accession number of SRP095080 (Prunus mahaleb CDR-1) and PRJNA704726 (P. cerasus $\times$ P. canescens Gisela 5).

Conflicts of Interest: The authors declare that they have no conflict of interest.

\begin{tabular}{ll}
\multicolumn{2}{l}{ Abbreviations } \\
DT & Drought-tolerant cherry rootstock \\
DS & Drought-susceptible cherry rootstock \\
TCA cycle & Tricarboxylic acid cycle \\
DEGs & Differentially expressed genes \\
PPI & Protein-Protein Interaction \\
ABA & Abscisic acid \\
SG & Stress group \\
CG & Control group \\
LWC & Relative water content \\
FPKM & Fragments Per Kilobase of transcript per Million mapped fragments \\
GO & Gene Ontology \\
KOG/COG & euKaryotic 87tssOrthologous Groups/Clusters of Orthologous Groups \\
KEGG & Kyoto Encyclopedia of Genes and Genomes \\
qRT-PCR & Quantitative real-time PCR \\
GC-MS & Gas chromatography-mass spectrometer \\
RI & Retention time index \\
QC & Quality control \\
PCA & Principal component analysis \\
OPLS-DA & Orthogonal projections to latent structures-discriminant analysis \\
VIP & Variable importance in the projection \\
CDS & Coding sequence \\
TFs & Transcription factors
\end{tabular}




\section{References}

1. Chaves, M.M.; Maroco, J.P.; Pereira, J.S. Understanding plant responses to drought—From genes to the whole plant. Funct. Plant Biol. 2003, 30, 239-264. [CrossRef]

2. Kucukyumuk, Z.; Erbas, S.; Erdal, I.; Baydar, H.; Eraslan, F. Effect of different nitrogen doses on plant growth, quality characteristics and nutrient concentrations of lavandin (Lavandula $\times$ intermedia Emeric ex Loisel. var. Super A). J. Essent. Oil Bear. Pl. 2015, 18, 36-43. [CrossRef]

3. Sivritepe, N.; Erturk, U.; Yerlikaya, C.; Turkan, I.; Bor, M.; Ozdemir, F. Response of the cherry rootstock to water stress induced in vitro. Biol. Plant. 2008, 52, 573-576. [CrossRef]

4. Cai, Y.; Zhao, X.; Hrotkó, K. Development of cherry growing in Shaanxi province of PR China. Acta Hortic. 2019, 1235, 239-244. [CrossRef]

5. Morandi, B.; Manfrini, L.; Lugli, S.; Tugnoli, A.; Boini, A.; Perulli, G.D.; Bresilla, K.; Venturi, M.; Corelli Grappadelli, L.J. Sweet cherry water relations and fruit production efficiency are affected by rootstock vigor. J. Plant Phys. 2019, 237, 43-50. [CrossRef] [PubMed]

6. Ranney, T.G.; Bassuk, N.L.; Whitlow, T.H. Osmotic adjustment and solute constituents in leaves and roots of water-stressed cherry (Prunus) trees. J. Am. Soc. Hortic. Sci. 1991, 116, 684-688. [CrossRef]

7. Guo, Y.; Yu, H.; Kong, D.; Yan, F.; Liu, D.; Zhang, Y. Effects of gradual soil drought stress on the growth, biomass partitioning, and chlorophyll fluorescence of Prunus mongolica seedlings. Turk. J. Biol. 2015, 39, 532-539. [CrossRef]

8. Arndt, S.K.; Wanek, W.; Clifford, S.C.; Popp, M. Contrasting adaptations to drought stress in field-grown Ziziphus mauritiana and Prunus persica trees: Water relations, osmotic adjustment and carbon isotope composition. Funct. Plant Biol. 2000, 27, 985-996. [CrossRef]

9. Kalefetoğlu, T.; Ekmekçi, Y. The effects of drought on plants and tolerance mechanisms. Gazi Univ. J. Sci. 2005, 18, 723-740.10.

10. Jiménez, S.; Dridi, J.; Gutiérrez, D.; Moret, D.; Irigoyen, J.J.; Moreno, M.A.; Gogorcena, Y. Physiological, biochemical and molecular responses in four Prunus rootstocks submitted to drought stress. Tree Physiol. 2013, 33, 1061-1075. [CrossRef]

11. Lang, G.A. Precocious, dwarfing, and productive-How will new cherry rootstocks impact the sweet cherry industry? HortTechnology 2000, 10, 719-725. [CrossRef]

12. Hrotko, K. Potentials in Prunus mahaleb L. for cherry rootstock breeding. Sci. Hortic. 2016, 205, 70-78. [CrossRef]

13. Faust, M.; Surányi, D. Origin and dissemination of cherry. Hort. Rev. 1997, 19, 263-317. [CrossRef]

14. Hrotko, K. Progress in cherry rootstock research. Acta Hortic. 2008, 795, 171-178. [CrossRef]

15. Bagati, S.; Mahajan, R.; Nazir, M.; Dar, A.A.; Zargar, S.M. Omics: A gateway towards abiotic stress tolerance. In Abiotic Stress-Mediated Sensing and Signaling In plants: An Omics Perspective; Springer: Singapore, 2018; pp. 1-45.

16. Arbona, V.; Manzi, M.; Ollas, C.; Gómez-Cadenas, A. Metabolomics as a tool to investigate abiotic stress tolerance in plants. Int. J. Mol. Sci. 2013, 14, 4885-4911. [CrossRef]

17. Park, C.H.; Yeo, H.J.; Park, Y.E.; Baek, S.-A.; Kim, J.K.; Park, S.U. Transcriptome analysis and metabolic profiling of Lycoris radiata. Biology 2019, 8, 63. [CrossRef] [PubMed]

18. Wang, J.; Rong, Z.; Bai, S.; Gao, X.; Min, L.; Wei, Y.; Chan, Z. Mongolian almond (Prunus mongolica Maxim): The morphophysiological, biochemical and transcriptomic response to drought stress. PLoS ONE 2015, 10, e0124442. [CrossRef] [PubMed]

19. Chang, B.; Ma, K.; Lu, Z.; Lu, J.; Cui, J.; Wang, L.; Jin, B. Physiological, transcriptomic, and metabolic responses of Ginkgo biloba L. to drought, salt, and heat stresses. Biomolecules 2020, 10, 1635. [CrossRef] [PubMed]

20. Campos, C.; Nobre, T.; Goss, M.J.; Faria, J.; Barrulas, P.; Carvalho, M. Transcriptome analysis of wheat roots reveals a differential regulation of stress responses related to arbuscular mycorrhizal fungi and soil disturbance. Biology 2019, 8, 93. [CrossRef]

21. You, J.; Zhang, Y.; Liu, A.; Li, D.; Wang, X.; Dossa, K.; Zhou, R.; Yu, J.; Zhang, Y.; Wang, L.; et al. Transcriptomic and metabolomic profiling of drought-tolerant and susceptible sesame genotypes in response to drought stress. BMC Plant Biol. 2019, 19. [CrossRef]

22. Pan, L.; Meng, C.; Wang, J.; Ma, X.; Fan, X.; Yang, Z.; Zhou, M.; Zhang, X. Integrated omics data of two annual ryegrass (Lolium multiflorum L.) genotypes reveals core metabolic processes under drought stress. BMC Plant Biol. 2018, 18. [CrossRef] [PubMed]

23. Glaubitz, U.; Li, X.; Schaedel, S.; Erban, A.; Sulpice, R.; Kopka, J.; Hincha, D.K.; Zuther, E. Integrated analysis of rice transcriptomic and metabolomic responses to elevated night temperatures identifies sensitivity- and tolerance-related profiles. Plant Cell Environ. 2017, 40, 121-137. [CrossRef]

24. Wedow, J.M.; Yendrek, C.R.; Mello, T.R.; Creste, S.; Martinez, C.A.; Ainsworth, E.A. Metabolite and transcript profiling of Guinea grass (Panicum maximum Jacq) response to elevated $\left[\mathrm{CO}_{2}\right.$ ] and temperature. Metabolomics 2019, 15. [CrossRef] [PubMed]

25. Hirai, M.Y.; Yano, M.; Goodenowe, D.B.; Kanaya, S.; Kimura, T.; Awazuhara, M.; Arita, M.; Fujiwara, T.; Saito, K. Integration of transcriptomics and metabolomics for understanding of global responses to nutritional stresses in Arabidopsis thaliana. P. Natl. A Sci. India. B. 2004, 101, 10205-10210. [CrossRef]

26. Pan, J.; Li, Z.; Dai, S.; Ding, H.; Wang, Q.; Li, X.; Ding, G.; Wang, P.; Guan, Y.; Liu, W. Integrative analyses of transcriptomics and metabolomics upon seed germination of foxtail millet in response to salinity. Sci. Rep. 2020, 10. [CrossRef]

27. Yan, Z.; Zuo, J.; Zhou, F.; Shi, J.; Xu, D.; Hu, W.; Jiang, A.; Liu, Y.; Wang, Q. Integrated analysis of transcriptomic and metabolomic data reveals the mechanism by which LED light irradiation extends the postharvest quality of pak-choi (Brassica campestris L. ssp. chinensis (L.) Makino var. communis Tsen et Lee). Biomolecules 2020, 10, 252. [CrossRef] [PubMed] 
28. Pascual, J.; Cañal, M.J.; Escandón, M.; Meijón, M.; Weckwerth, W.; Valledor, L. Integrated physiological, proteomic, and metabolomic analysis of UV stress responses and adaptation mechanisms in Pinus radiata. Mol. Cell. Proteomics 2017, 16, 485-501. [CrossRef] [PubMed]

29. Shirasawa, K.; Isuzugawa, K.; Ikenaga, M.; Saito, Y.; Yamamoto, T.; Hirakawa, H.; Isobe, S. The genome sequence of sweet cherry (Prunus avium) for use in genomics-assisted breeding. DNA Res. 2017, 24, 499-508. [CrossRef]

30. Anders, S.; Huber, W. Differential expression analysis for sequence count data. Nat. Prec. 2010. [CrossRef]

31. Feng, Y.; Liang, C.; Li, B.; Wan, T.; Liu, T.; Cai, Y. Differential expression profiles and pathways of genes in drought resistant tree species Prunus mahaleb roots and leaves in response to drought stress. Sci. Hortic. 2017, 226, 75-84. [CrossRef]

32. Sharma, A.; Shahzad, B.; Kumar, V.; Kohli, S.K.; Sidhu, G.P.S.; Bali, A.S.; Handa, N.; Kapoor, D.; Bhardwaj, R.; Zheng, B. Phytohormones regulate accumulation of osmolytes under abiotic stress. Biomolecules 2019, 9, 285. [CrossRef]

33. Santisree, P.; Bhatnagar-Mathur, P.; Sharma, K.K. NO to drought-multifunctional role of nitric oxide in plant drought: Do we have all the answers? Plant Sci. (Amsterdam, Neth.) 2015, 239, 44-55. [CrossRef] [PubMed]

34. Reddy, A.R.; Chaitanya, K.V.; Vivekanandan, M. Drought-induced responses of photosynthesis and antioxidant metabolism in higher plants. J. Plant Physiol. 2004, 161, 1189-1202. [CrossRef]

35. Rathinasabapathi, B. Metabolic engineering for stress tolerance: Installing osmoprotectant synthesis pathways. Ann. Bot. 2000, 86, 709-716. [CrossRef]

36. Hura, T.; Grzesiak, S.; Hura, K.; Thiemt, E.; Tokarz, K.; Wedzony, M. Physiological and biochemical tools useful in droughttolerance detection in genotypes of winter triticale: Accumulation of ferulic acid correlates with drought tolerance. Ann. Bot. 2007, 100, 767-775. [CrossRef] [PubMed]

37. Ma, X.; Xia, H.; Liu, Y.; Wei, H.; Zheng, X.; Song, C.; Chen, L.; Liu, H.; Luo, L. Transcriptomic and metabolomic studies disclose key metabolism pathways contributing to well-maintained photosynthesis under the drought and the consequent drought-tolerance in rice. Front. Plant 2016, 7. [CrossRef] [PubMed]

38. Singh, M.; Kumar, J.; Singh, S.; Singh, V.P.; Prasad, S.M. Roles of osmoprotectants in improving salinity and drought tolerance in plants: A review. Rev. Environ. Sci. Bio. 2015, 14, 407-426. [CrossRef]

39. Bohnert, H.J.; Jensen, R.G. Strategies for engineering water-stress tolerance in plants. Trends Biotechnol. 1996, 14, 89-97. [CrossRef]

40. Ashraf, M.; Foolad, M.R. Roles of glycine betaine and proline in improving plant abiotic stress resistance. Environ. Exp. Bot. 2007, 59, 206-216. [CrossRef]

41. Sieciechowicz, K.A.; Joy, K.W.; Ireland, R.J. The metabolism of asparagine in plants. Phytochemistry 1988, 27, 663-671. [CrossRef]

42. Lea, P.J.; Sodek, L.; Parry, M.A.J.; Shewry, P.R.; Halford, N.G. Asparagine in plants. Ann. Appl. Biol. 2007, 150, 1-26. [CrossRef]

43. Toumi, I.; Gargouri, M.; Nouairi, I.; Moschou, P.N.; Salem-Fnayou, A.B.; Mliki, A.; Zarrouk, M.; Ghorbel, A. Water stress induced changes in the leaf lipid composition of four grapevine genotypes with different drought tolerance. Biol. Plant. 2008, 52, 161-164. [CrossRef]

44. Scotti-Campos, P.; Pham-Thi, A.-T.; Semedo, J.; Pais, I.; Ramalho, J.; Matos, M. Physiological responses and membrane integrity in three Vigna genotypes with contrasting drought tolerance. Emir. J. Food Agric. 2013, 25, 1002. [CrossRef]

45. Scotti-Campos, P.; Pais, I.P.; Partelli, F.L.; Batista-Santos, P.; Ramalho, J.C. Phospholipids profile in chloroplasts of Coffea spp. genotypes differing in cold acclimation ability. J. Plant Physiol. 2014, 171, 243-249. [CrossRef] [PubMed]

46. Partelli, F.L.; Vieira, H.D.; Pais, I.P.; Quartin, V.L.; Ramalho, J.C. Chloroplast membrane lipids from Coffea sp. under low positive temperatures. In Proceedings of the 22nd International Conference on Coffee Science, Campinas, Brazil, 14-19 September 2009; pp. 891-898.

47. Scotti-Campos, P.; Pham-Thi, A.-T. Correlation between total lipids, linolenic acid and membrane injury under PEG-induced dehydration in leaves of Vigna genotypes differing in drought resistance. Emir. J. Food Agric. 2016, 28, 485. [CrossRef]

48. Xu, F.; Zhang, D.; Zhu, F.; Tang, H.; Lv, X.; Cheng, J.; Xie, H.; Lin, H. A novel role for cyanide in the control of cucumber (Cucumis sativus L.) seedlings response to environmental stress. Plant Cell Environ. 2012, 35, 1983-1997. [CrossRef] [PubMed]

49. O'Leary, B.; Preston, G.M.; Sweetlove, L.J. Increased $\beta$-cyanoalanine nitrilase activity improves cyanide tolerance and assimilation in Arabidopsis. Mol. Plant 2014, 7, 231-243. [CrossRef]

50. Yip, W.-K.; Yang, S.F. Cyanide metabolism in relation to ethylene production in plant tissues. Plant Physiol. 1988, 88, 473-476. [CrossRef] [PubMed]

51. Zhang, J.; Chen, G.; Zhao, P.; Zhou, Q.; Zhao, X. The abundance of certain metabolites responds to drought stress in the highly drought tolerant plant Caragana korshinskii. Acta Physiol. Plant. 2017, 39, 116. [CrossRef]

52. Barnaby, J.Y.; Fleisher, D.H.; Singh, S.K.; Sicher, R.C.; Reddy, V.R. Combined effects of drought and $\mathrm{CO}_{2}$ enrichment on foliar metabolites of potato (Solanum tuberosum L.) cultivars. J. Plant Interact. 2019, 14, 110-118. [CrossRef]

53. Khan, N.; Bano, A.; Rahman, M.A.; Rathinasabapathi, B.; Babar, M.A. UPLC-HRMS-based untargeted metabolic profiling reveals changes in chickpea (Cicer arietinum) metabolome following long-term drought stress. Plant Cell Environ. 2019, 42, 115-132. [CrossRef] [PubMed]

54. Sabella, E.; Luvisi, A.; Aprile, A.; Negro, C.; Vergine, M.; Nicolì, F.; Miceli, A.; De Bellis, L. Xylella fastidiosa induces differential expression of lignification related-genes and lignin accumulation in tolerant olive trees cv. Leccino. J. Plant Physiol. 2018, 220, 60-68. [CrossRef] [PubMed]

55. Peltier, J.P.; Marigo, D.; Marigo, G. Involvement of malate and mannitol in the diurnal regulation of the water status in members of Oleaceae. Trees 1997, 12, 27-34. [CrossRef] 
56. Rahmati, M.; Vercambre, G.; Davarynejad, G.; Bannayan, M.; Azizi, M.; Génard, M. Water scarcity conditions affect peach fruit size and polyphenol contents more severely than other fruit quality traits. J. Sci. Food Agric. 2015, 95, 1055-1065. [CrossRef] [PubMed]

57. Larher, F.R.; Lugan, R.; Gagneul, D.; Guyot, S.; Monnier, C.; Lespinasse, Y.; Bouchereau, A. A reassessment of the prevalent organic solutes constitutively accumulated and potentially involved in osmotic adjustment in pear leaves. Environ. Exp. Bot. 2009, 66, 230-241. [CrossRef]

58. Gargallo-Garriga, A.; Sardans, J.; Pérez-Trujillo, M.; Oravec, M.; Urban, O.; Jentsch, A.; Kreyling, J.; Beierkuhnlein, C.; Parella, T.; Peñuelas, J. Warming differentially influences the effects of drought on stoichiometry and metabolomics in shoots and roots. New Phytol. 2015, 207, 591-603. [CrossRef] [PubMed]

59. Passarinho, J.A.P.; Lamosa, P.; Baeta, J.P.; Santos, H.; Ricardo, C.P.P. Annual changes in the concentration of minerals and organic compounds of Quercus suber leaves. Physiol. Plant 2006, 127, 100-110. [CrossRef]

60. Kamzolova, S.V.; Vinokurova, N.G.; Dedyukhina, E.G.; Samoilenko, V.A.; Lunina, J.N.; Mironov, A.A.; Allayarov, R.K.; Morgunov, I.G. The peculiarities of succinic acid production from rapeseed oil by Yarrowia lipolytica yeast. Appl. Microbiol. Biotechnol. 2014, 98, 4149-4157. [CrossRef]

61. Morgunov, I.G.; Kamzolova, S.V.; Dedyukhina, E.G.; Chistyakova, T.I.; Lunina, J.N.; Mironov, A.A.; Stepanova, N.N.; Shemshura, O.N.; Vainshtein, M.B. Application of organic acids for plant protection against phytopathogens. Appl. Microbiol. Biotechnol. 2016, 101, 921-932. [CrossRef] [PubMed]

62. Schwartz, H. Method for Regulating the Growth of Plants. U.S. Patent US3326659A, 20 June 1967.

63. Chung, N.; Mao, C.; Heitman, J.; Hannun, Y.A.; Obeid, L.M. Phytosphingosine as a specific inhibitor of growth and nutrient import in Saccharomyces cerevisiae. J. Biol. Chem. 2001, 276, 35614-35621. [CrossRef] [PubMed]

64. Peer, M.; Stegmann, M.; Mueller, M.J.; Waller, F. Pseudomonas syringaeinfection triggers de novo synthesis of phytosphingosine from sphinganine in Arabidopsis thaliana. FEBS Lett. 2010, 584, 4053-4056. [CrossRef] [PubMed]

65. Michaelson, L.V.; Napier, J.A.; Molino, D.; Faure, J.-D. Plant sphingolipids: Their importance in cellular organization and adaption. Biochim. Biophys. Acta 2016, 1861, 1329-1335. [CrossRef] [PubMed]

66. Niinemets, Ü. Uncovering the hidden facets of drought stress: Secondary metabolites make the difference. Tree Physiol. 2016, 36, 129-132. [CrossRef] [PubMed]

67. Krasensky, J.; Jonak, C. Drought, salt, and temperature stress-induced metabolic rearrangements and regulatory networks. J. Exp. Bot. 2012, 63, 1593. [CrossRef]

68. Chen, Y.; Liu, W.; Su, Y.; Cui, J.; Zhang, Z.; Yuan, M.; Zhang, H.; Yuan, S. Different response of photosystem II to short and long-term drought stress in Arabidopsis thaliana. Physiol. Plant 2016, 158, 225-235. [CrossRef]

69. Pommerrenig, B.; Ludewig, F.; Cvetkovic, J.; Trentmann, O.; Klemens, P.A.; Neuhaus, H.E. In concert: Orchestrated changes in carbohydrate homeostasis are critical for plant abiotic stress tolerance. Plant Cell Physiol. 2018, 59, 1290-1299. [CrossRef] [PubMed]

70. Janska, A.; Marsík, P.; Zelenková, S.; Ovesná, J. Cold stress and acclimation-What is important for metabolic adjustment? Plant Biol. 2010, 12, 395-405. [CrossRef] [PubMed] 